\title{
INTASC AND MODALITY ON SPEAKING: HOW EFFECTIVE?
}

\author{
Muliani $^{1)}$, Dedi Sumarsono ${ }^{2)}$ \\ FPBS IKIP Mataram \\ muliani@ikipmataram.ac.id ${ }^{1 \mathbf{1}}$, dedisumarsono@ikipmataram.ac.id ${ }^{2)}$
}

\begin{abstract}
The concern of this current research is based on the consideration that Speaking is urgently needed in acquiring the target language such as English. Then, the problem is mostly dealing with the ability to speak regarding the culture of the target language aiming at getting the approximation to the language being acquired. InTASC standard cores are offered to assist the students of SMAN 1 Kopang in which the standards were implemented that it is expected they are able to communicate in English. Eventually, it was found that InTASC standard cores are effective to assist the students' speaking in which the standards meet the whole indicators of Speaking.
\end{abstract}

Keywords: INTASC Standards, Speaking, Modality

\section{INTRODUCTION}

This current research take Speaking skill since this skill needs more treatment particularly for the candidate of teachers in which it is considered that Speaking is not about to practice and being understandable by others, but it is more to the wellformness of the sentences uttered by the speakers. The well-formeness deals with the appropriateness of the spoken expressions in which it does not only consider the appropriateness sequence and structure of the sentence, but the referent and the cultural (contextual) consideration are also taken as the basic consideration. In other words, culturally speaking is the main urgent reason for carrying this research out. Thus, this teaching model aims to raise the level of learning in the classroom where Speaking is not considered to practice, but this is more related to speaking culturally regarding the Modality expressions.

Teaching speaking to Alonso (2014: 155) constitutes a central issue in second language learning because it contributed to success in the acquisition of the second language in which teachers play an essential role in the acquisition of this skill in that they were in charge of promoting meaningful communication in the classroom. Speaking is neither only to practice, but it is more dealing with the ability to speak culturally on the language being spoken because it was a main consideration to take culturally speaking into account as Oatey and Spencer (2000: 1) stated that different culture may have different convention as to what is appropriate in what contexts. Martin and Nakayama (2010: 95) stated that culture influences communication, and vice versa in which cultural groups influence the process by which the perception of reality is created and maintained. It can be pointed out that the culture of the language must be considered as the language being learned and taught. Next to that, Warsi (- : 39) stated that culture is defined as the set of shared attitudes, values, goals, and practices that characterizes an institution, organization or group. Due to those reasons, it could be noted that culturally speaking is concerned with how to speak regarding the attitudes, the behavior, etc of the target language in which on this current 
research modality is one part of language expressions has a very close relation to culture as the target learners speak the language, in this case, English because modality goes beyond the tense of the language, it goes further concerning the aspect of the language because it also deals with the interpretation and cultural interpretation must be taken into account.

Regarding modality in relation to culturally speaking, as Papafragou (2000: 3 ) stated the problem of modality is on their preferred interpretation. Next to that, Fintel, (2006: 1) stated that Modality is a category of linguistic meaning having to do with the expression possibility and necessity. It can be pointed out that modality in Speaking must be taken into a consideration as something to learn and teach to reveal the problem regarding the interpretation on the usage of the modalities culturally.

Council of Chief State School Officers in April 2011established the Interstate Teacher Assessment and Support Consortium (InTASC) Model Core aiming at raising the level of learning in the classroom in which as CCSSO team (2011: 3) stated that teachers need to provide multiple approaches to learning for each student. Then, it was expected that learners more active role in determining what they learned, how they learn it, and how they can demonstrate their learning. It also stated (CCSO team,2011: 4) that students are also encouraged to interact with peers to accomplish their learning goals.

Henson (2009: 34) stated that this model of teaching was established to provide support to new teachers and raise the levels of learning in U.S classroom. Due to that reason, this current research implemented this teaching model for the candidates of English teachers where it was expected that they have a good competence of Speaking in which they can speak culturally regarding English Modality.

As it has been carried out on the previous research by Muliani, et al (20152016), this current research also deals with the 10 standards of InTASC in which standard 1-2 deals with formative assessment to know the students' prior knowledge, strength, and their diversity of learning. Standard 3-7 deals with the implementation of the content knowledge regarding Speaking concerning on Modality expressions, while standard 8-10 deals with summative assessment and the reflection of the implementation of the whole standards.

\section{RESEARCH METHOD}

\section{Research Design}

The research method that used in this study was experimental research. According to Kerlinger (1973: 315) an experimental study is a study in which the investigator manipulates at least one independent variable. Marczyk, DeMatteo, Festingers (2005: 124) stated that experimental study is one which studies participant are randomly assigned to experimental and control groups.

The purpose of an experimental study was to investigate the correlation between cause and effect and how far its correlation is by giving certain treatment to experimental class and to control class as the comparison. This research was a quasi experimental research because random assignment was not used in determining or distributing sample into experiment class or group and control class or group. 
The research design used for the research is a simple factorial design $2 \times 2$ by technique of Multifactor Analysis of Variance (ANOVA). The research then can be designed in the table 1 .

\section{Table 1. Design of 2x2 Multifactor Analysis of Variance}

\begin{tabular}{|ll|c|c|}
\hline $\begin{array}{r}\text { Teaching } \\
\text { Method }\end{array}$ & $\begin{array}{r}\text { INTASC } \\
\text { Standards } \\
\text { Core } \\
\left(\mathrm{A}_{1}\right)\end{array}$ & $\begin{array}{c}\text { Conventional } \\
\text { Method }\left(\mathrm{A}_{2}\right)\end{array}$ \\
\hline $\begin{array}{l}\text { Modality } \\
\left(\mathrm{B}_{1}\right)\end{array}$ & Modality & $\mathrm{A}_{1} \mathrm{~B}_{1}$ & $\mathrm{~A}_{2} \mathrm{~B}_{1}$ \\
\hline $\begin{array}{l}\text { Low } \\
\left(\mathrm{B}_{2}\right)\end{array}$ & Modality & $\mathrm{A}_{1} \mathrm{~B}_{2}$ & $\mathrm{~A}_{2} \mathrm{~B}_{2}$ \\
\hline
\end{tabular}

\section{Population and Sample \\ Population}

Population is all individuals of interest to the researcher (Marcczyk, DeMatteo, Festingers, 2005: 18). Meanwhile, Sugiono (2008: 80) stated that population is generalization area consisting of object/subject that has certain quality and characteristics which is determined by the researcher to be studied. The population of this research is the students SMAN 1 Kopang.

\section{Sample}

According to Marcyzyk, DeMatteo, Festinger (2005: 18) sample is a study of a subset of the population. The sample of the research are two classes of the secondgrade students of SMAN 1 Kopang.

\section{Instruments}

The instrument used in collecting the data was Speaking test. They are oral speaking test for speaking skill and test of modality. In order to know the students' modality score, the researcher distributed some test to the students. Furthermore, to know the students speaking skill, the students are given a speaking test in the form of oral interview test. The students' speaking test was arranged based on the indicators at the blueprint, formulated based on construct. The items of the students' speaking test will be tried out first, in order to know its readability.

\section{Data Analysis}

The techniques of analyzing data that used for the research was descriptive analysis and inferential analysis. Descriptive analysis is used to know: Mean, Median, Mode, and Standard deviation of the speaking test. Before conducting ANOVA test, normality and homogeneity test must be conducted. Normality is conducted to know whether the sample distributes normally or not. To examine the normality, Liliefors test is used. Meanwhile, to examine the homogeneity test, Barlet test is used.

\section{FINDING AND DISCUSSION Research Finding}

The researcher focuses on the statistical analysis of the data obtained. This analysis showed how to calculate the data before they are discussed and stated at conclusion. The discussion was continued to the analysis and the interpretation of the investigation.

To find out the effectiveness of the research, the researcher intended to analyze the data obtained from students' result. This study was aimed at finding out the research problem that has been stated in previous chapter "Is INTASC Standard effective in teaching speaking at second grade of SMAN 1 KOPANG? 
a) Descriptive Analysis

1) The result of Experimental Group

Table 2. Descriptive Statistic of

Experimental Class

\begin{tabular}{|l|r|r|}
\hline \multicolumn{2}{c|}{ Statistics } \\
\hline Experimental & Kelas \\
\hline N Valid & 23 & 23 \\
\multicolumn{1}{|c|}{ Missing } & 0 & 0 \\
Mean & 56.17 & 1.00 \\
Median & 56.00 & 1.00 \\
Mode & 48 & 1 \\
Std. Deviation & 8.569 & .000 \\
Variance & 73.423 & .000 \\
Range & 24 & 0 \\
Minimum & 44 & 1 \\
Maximum & 68 & 1 \\
Sum & 1292 & 23 \\
\hline
\end{tabular}

The data description of experimental group showed that the highest score was 68 and the lowest score was 44. Then the mean score was 56,17 , the value of mode was 48 , the value of median was 56,00 , range was 24 and the value of standard deviation was 8,569 .

2) The result of Control Group

Table 3. Descriptive Statistic of Control Group

\begin{tabular}{|l|r|r|}
\hline \multicolumn{2}{|c|}{ Statistics } \\
\hline N $\quad$ Valid & \multicolumn{1}{|c|}{ Control } & \multicolumn{1}{|c|}{ Kelas } \\
\hline \multicolumn{1}{|c|}{ Missing } & 0 & 26 \\
Mean & 46.77 & 0 \\
Median & 46.00 & 2.00 \\
Mode & 52 & 2.00 \\
Std. Deviation & 9.035 & 2 \\
Variance & 81.625 & .000 \\
Range & 32 & .000 \\
Minimum & 32 & 0 \\
Maximum & 64 & 2 \\
Sum & 1216 & 2 \\
\hline
\end{tabular}

The data description of control group showed that the highest score was 64 and the lowest score was 32 . Then the mean score was 46,77 , the value of mode was 52 , the value of median was 46,00 , range was 32 and the value of standard deviation was 9,035 .

3) The High Result of Modality Table 4. Descriptive Statistic of Modality High Result

\begin{tabular}{|l|r|r|}
\hline \multicolumn{2}{|c|}{ Statistics } \\
\hline N $\quad$ Highscore & \multicolumn{1}{|c|}{ Kelas } \\
\hline \multicolumn{1}{|c|}{ Missing } & 20 & 20 \\
Mean & 0 & 0 \\
Median & 56.40 & 3.00 \\
Mode & 56.00 & 3.00 \\
Std. Deviation & $56^{\mathrm{a}}$ & 3 \\
Variance & 10.210 & .000 \\
Range & 104.253 & .000 \\
Minimum & 36 & 0 \\
Maximum & 32 & 3 \\
Sum & 68 & 3 \\
\hline
\end{tabular}

The data description the high result of the students in experimental and control group showed that the highest score was 68 and the lowest score was 32 . Then the mean score was 56,40, the value of mode was 56 , the value of median was 56,00 , range was 36 and the value of standard deviation was 10,210 .

4) The Low Result of Modality

Table 5. Descriptive Statistic of Modality Low Result

\begin{tabular}{|rl|r|r|}
\multicolumn{3}{|c|}{ Statistics } \\
\hline & Low score & Kelas \\
\hline N & Valid & 29 & 29 \\
& Missing & 0 & 0
\end{tabular}




\begin{tabular}{l|r|r|} 
Mean & 47.59 & 4.00 \\
Median & 48.00 & 4.00 \\
Mode & 48 & 4 \\
Std. Deviation & 8.095 & .000 \\
Variance & 65.537 & .000 \\
Range & 32 & 0 \\
Minimum & 32 & 4 \\
Maximum & 64 & 4 \\
Sum & 1380 & 116 \\
\hline
\end{tabular}

The data description the low result of experimental group and control group showed that the highest score was 64 and the lowest score was 32 . Then the mean score was 47.59 , the value of mode was 48 , the value of median was 48,00 , range was 32 and the value of standard deviation was 8,095 .

b) Normality and Homogeneity Data

1) Normality Test

Normality test was purposed to test whether in a test of t-test has normal distribution or not, if the level of significance was greater than 0,05 meaning that the data was normal, and if the level of significance was less than 0,05 meaning that the data was abnormal. The test of normality can be seen in the table as follows:

Table 6. One-Sample KolmogorovSmirnov Test

\begin{tabular}{|ll|r|r|}
\hline & & Modality & Speaking \\
\hline $\mathrm{N}$ & & 49 & 49 \\
Normal & Mean & 51.18 & 51.18 \\
Parameters & St,b. Deviation & 9.932 & 9.932 \\
Most Extreme & Absolute & .116 & .116 \\
Differences & Positive & .116 & .116 \\
& Negative & -.085 & -.085 \\
& .809 & .809 \\
Kolmogorov-Smirnov Z & .530 & .530 \\
Asymp. Sig. (2-tailed) & & \\
\hline
\end{tabular}

Based on the table above, it showed the significant of Modality is $0,530>0,05$ dan the significant of Speaking is $0,530>0,05$, so that could be concluded that the data of speaking and modality is normal distribution.

\section{2) Homogeneity Test}

Homogeneity Test of variants was seen from Levene'stest result, as shown in the following table.

Table 7. Levene's Test of Equality of Error Variances ${ }^{\mathrm{a}}$

Dependent Variable:Speaking

\begin{tabular}{|c|r|r|r|}
\hline F & df1 & \multicolumn{1}{|c|}{ df2 } & \multicolumn{1}{c|}{ Sig. } \\
\hline 4.857 & 17 & 31 & .000 \\
\hline
\end{tabular}

Tests the null hypothesis that the error variance of the dependent variable is equal across groups.

a. Design: Intercept + Metode + Modality + Metode * Modality

Based on the output of SPSS Statistic17, the result showed that significant of homogeneity is 0,000 . Because the significant $0,000<0,05$, so it could be concluded that the variant of speaking is not homogeneous (heterogeneous). So that, the assumption of homogeneity in Two-Way Anova is not fulfilled. In this case, using the ANOVA test can ignore the homogeneity of the data, because it is too difficult to get the same variation of scores in the two groups that are subjected to different treatments, so that to returns the results of the normality test, where in the next explanation on normality test states that the significant of speaking and modality concluded that modality was "normal" distribution. 
c) Inferential Statistic Analysis

Table 8. Descriptive Statistic of Post-Test

\begin{tabular}{|c|l|r|r|}
\hline Modality & \multicolumn{1}{|c|}{ Method } & Mean & $\begin{array}{c}\text { Std. } \\
\text { Deviation }\end{array}$ \\
\hline \multirow{3}{*}{ High } & InTASC & 60.86 & 7.048 \\
\cline { 2 - 4 } & Talking & 46.00 & 9.033 \\
\cline { 2 - 4 } & Total & 53.43 & 10.210 \\
\hline \multirow{3}{*}{ Low } & InTASC & 48.89 & 4.807 \\
\cline { 2 - 4 } & Talking Chips & 47.00 & 9.257 \\
\cline { 2 - 4 } & Total & 47.94 & 8.095 \\
\hline \multirow{2}{*}{ Total } & InTASC & 56.17 & 8.569 \\
\hline \multirow{2}{*}{} & Talking Chips & 46.77 & 9.035 \\
\hline
\end{tabular}

The scores of the four groups on the dependent variable, the students' speaking skill shows that the mean score of InTASC, 56,17 is compared with Talking Chips, 46,77, it could be found that the differences between these means are 9,40 points. Therefore, it could be concluded that InTASC is more effective than Talking Chips. It has the positive effect on the students' speaking skill.

In addition, the mean score for the two high-modality groups are 53,43, and the mean score for the low-modality groups are 47,94. Since this difference is 5,49 points, it could be assumed that there is an effect caused by the level of modality. The high modality group has a markedly higher mean score. Thus, regardless of teaching method used, the high-modality groups perform better than the low-modality group.

Teaching methods and students' modality are independent of each other. The existence of sufficient interaction could be illustrated graphically in Figure 1 and significant differences in students' speaking skills have been statistically proven.

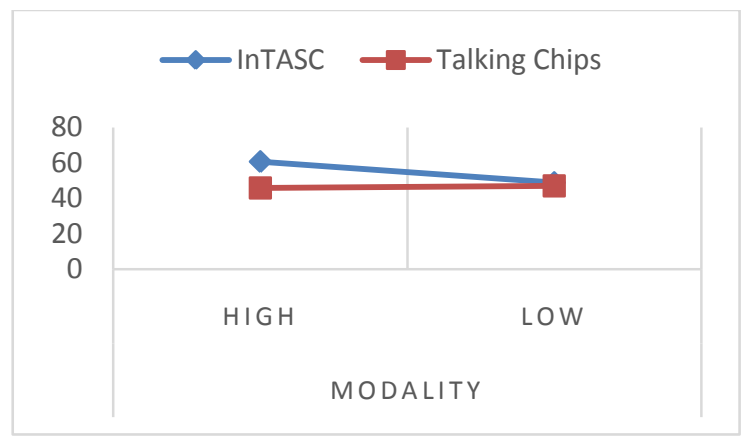

Figure 1. Illustration Sufficient of Interaction between Teaching Method and Students' Modality

The result of Two Way Anova are elaborated in Table 9.

Table 9. Tests of Between-Subjects Effects Dependent Variable:Speaking

\begin{tabular}{|l|r|r|r|r|r|}
\hline Source & $\begin{array}{r}\text { Type III } \\
\text { Sum of } \\
\text { Squares }\end{array}$ & Df & $\begin{array}{c}\text { Mean } \\
\text { Square }\end{array}$ & $\mathrm{F}$ & Sig. \\
\hline $\begin{array}{l}\text { Corrected } \\
\text { Model } \\
\text { Intercept }\end{array}$ & $\begin{array}{r}4164.680 \\
\mathrm{a}\end{array}$ & 17 & 244.981 & 13.308 & .000 \\
Metode & 94.457 & 1 & 94.457 & 5.131 & .031 \\
\hline Modality & 2230.873 & 9 & 247.875 & 13.465 & .000 \\
\hline $\begin{array}{l}\text { Metode * } \\
\text { Modality }\end{array}$ & 485.027 & 7 & 69.290 & 3.764 & .005 \\
\hline Error & 570.667 & 31 & 18.409 & & \\
\hline Total & 133104.0 & 49 & & & \\
\hline Corrected & 4735.347 & 48 & & & \\
\hline Total & & & & & \\
\hline
\end{tabular}

a. $\mathrm{R}$ Squared $=.879$ (Adjusted R Squared $=.813$

Based on the table above, on the first F-Ratio it could be concluded that there is a difference of significant in InTASC toward Students' Speaking because sign. $0.031<0.05$. So, the hypothesis which states that there is a difference of significant in InTASC toward Speaking is accepted. In the table.8 that those students who are treated under InTASC obtain a combine mean of 56,17 as compared with a mean of 46,77 for those students 
who are treated under Talking Chips. Since it is obtained a significant F-Test for the difference, it can be concluded that under the different modality, InTASC improves the students' speaking skill better.

The second F-Ratio summarized that there is a difference of significant of students with high modality towards speaking, because sign. $0.00<0.05$. So, the hypothesis which states that there is a difference of significant in high modality towards speaking is accepted. From the significance of this F-Test, it could be inferred that the difference between speaking skill of the students who have high and low modality is beyond expectation. In addition, examining the data that presented in Table.8, it could be seen that those students who have high modality obtain a combined mean of 53,43 as compared with a mean of 47,94 for those students who have low modality. Since it is obtained a significant F-test for the difference, it can be concluded that under the same teaching method, a higher speaking skill could be expected when the students have high modality than when they have low modality.

The third F-Ratio summarized that there is an interaction between the teaching method and the modality toward speaking, because the significant $0.05 \leq 0.05$, so the hypothesis which states that there is an interaction between the teaching method and the modality toward speaking is accepted. From the significant, this study shows that the main effect of InTASC as the teaching method with using modality which is the main assessment of teaching method in speaking skill has an interaction, it is also seen from the assessment of the high and low scores of modality, it could be concluded that the result shows the students' speaking skill taught by using InTASC better than students' speaking skill taught by using Talking Chips.

INTASC model is a model of teaching and learning English which stands for Interstate New Teachers Assessment and Support Consortium developed by The Council of Chief State School Officers is a nonpartisan, nationwide, non-profit organization of public officials who are working in developing teaching standards aiming at raising the level of learning in the classroom which consequently will improve the competence of the students. On the article written by Henson (2009: 34).

The implementation of InTASC Standard had created a good situation for the students during the teaching and learning process since the students got the opportunity to interact both with other students and with the teacher. The teacher-student and studentsstudents interaction could run well during the activities. The interaction was beneficial for the students because by the students could share and discuss the task together. As the result the students felt more comfortable in learning because the group work can minimize the anxiety with the difficulties, they found during the learning process. In line with that, it could be said InTASC Standard is believed to be effective to teaching speaking. 
According to Mandel (2000: p.5) who stated that "Learning to be a better speaker is similar to learning any activity". It means that how the students can learn speaking in many ways, one of them is modality. As Klein, at al (2006: p. 1) stated that "The notion of modality has been used in different ways in the literature. It is occasionally used in a very broad sense, such as to refer to any kind of speaker modification of a state of affairs, even including dimensions such as tense and aspect". Thus, it can be said that there is a relationship between how learn modality by learning speaking, because modality discusses how to use modal that could be find in students' daily activities, learning of modals, showing that students are sensitive to the subtlety of meaning and range of forms in the languages to which they are exposed.

In addition, the finding shows that both students who are taught the Talking Chips and InTASC gains better achievement in speaking if they have high score of modality. Therefore, it is suggested that the InTASC is effective in enhancing speaking skill of the students who have high or low modality to applied more effectiveness of InTASCunder the influence of how much the students understand the used of modality in their daily activity.

d) Tuckey Test

Tuckey test is a single step multiple comparison procedure and statistical used in this discussion, there are 10 (ten) mean value from the result of modality test that appear often in multiple comparison table in Tuckey test namely $32,36,40,44,48,52,56$,
60,64 , and 68. It could be concluded that on each mean value has a significant difference.

\section{CONCLUSION}

Based on the results of the elaboration on the three significant F-ratio results, indicating that InTASC influence students' speaking skills better than Talking Chips. Then, the students'high and low modality, also affect students' speaking skill. It also found that InTASC, Talking Chips, and Modality have a combine effect on the students' speaking skill. In other words, the three variables have strong enough interactions towards students' speaking skill.

InTASC Standard can be one of method in teaching speaking because the teacher gives the students an opportunity to interact with the other. It also provides the different kind of activities. So, the student more actives in class and confidences during the teaching and learning process so that their speaking skill level improve too. And also, by supporting the learning process with the used of a picture as a media was effective to engage students' attention. Most of students were interested more in speaking by being given some opinion about the picture. It helps students to remember the material easily than before. And the pictures are useful for the students to make some prediction about the' materials, they are learning and make them easier to remembers the materials. It implies that picture can help the students to understand better, and the picture can help them dealing with the task given, then the student could enrich their vocabulary. 


\section{ACKNOWLEDGMENT}

The great appreciation goes to IKIP Mataram which has funded this research. Next to that, the best appreciation also goes to the LPPM team in which they have supported this research in which it eventually is accomplished. Finally, it is expected that the result of this research can contribute to the enhancement of the quality teaching and learning processes of English to assist the students to get their approximation to English as the target language. Lastly, any uncountable support is appreciated quite highly.

\section{REFERENCES}

Alonso, Alonso, Rosa. (2014). Teaching Speaking: an Exploratory Study in Two Academic Contexts. Po $\mathrm{r} \mathrm{t}$ a $\mathrm{Li}$ n g u a r u m. ISSN: 1697-7467 page 145-160.

Anna, Papafragou. (2000). Modality: Issues in the Semantics: SemanticsPragmatics Interface. Oxford, England: Elsevier.

Council of Chief State School Offcers. (2011). Interstate Teacher Assessment and Support Consortium (InTASC) Model Core Teaching Standards: A Resource for State Dialogue. Washington, DC: Author.

Kerlinger, Fred, N. (1973). Foundations of Behavioral Research. New York: Holt, Rinehart, and Winston, Inc.

Kai von, Fintel. (2006). Modality and Language. In Encyclopedia of Philosophy - Second Edition, edited by Donald M. Borchert. Detroit: MacMillan Reference USA. Most recent version online at http://mit.edu/fintel/www/modality.p df.
Henson, Ken. (2009). Making the Most of INTASC Standards. SRATE Journal "Vol.18 Number 2" page 34-40.

Marczyk, G., DeMatteo, D., \& Festinger, D. (2005). Essentials of Research Design and Methodology. New Jersey: John Wiley and Sons. Inc.

Martin, N, Judith. Nakayama, K, Thomas. (2010). Intercultural Communication in Context. New York: The McGraw-Hill Companies, Inc.

Muliani. Sumarsono, Dedi. (2013). The Acquisition of English Modality by the English Department Students of IKIP Mataram. Journal of Languages and Language Teaching. "ISSN: 2339-0810 Vol. 2" page 109113.

Muliani. Maurisa, Sofia. (2014). The Acquisition of the Agent-Oriented Modality Types in L2 English Postgraduate Students' Expressions.Jurnal Pendidikan, LPPM IKIP Mataram; vol.13 no.3. September 2014. ISSN: 1412-6087.

Muliani. Maurisa, Sofia. Nurusshobah. (2015). Developing Teaching English Modality Competence by Applying InTASC Standards at the English Department Students of IKIP Mataram. Proceeding the 62nd TEFLIN No: 978-602-294-066-1.

Oatey, Spencer, Helen (ed). (2000). Culturally Speaking. Managing Rapport Through Talk Across Cultures. London and New York: Continuum.

Sugiyono, (2008). Metode Penelitian Kunatitatif Kualitatif dan $R \& D$. Bandung. Alfabeta.

Tuckman, Bruce, W. (1978). Conducting Educational Research. New York: Harcourt Brace Jovanovich, Inc. 
Warsi, M.J. - Culturally Speaking: Should Culture be an Integral Part of Language Pedagogy? SACS Vol. 2

No. $\quad 2 \quad$ pp39-46.

Washington University in St. Louis 3

9 E-mail: mwarsi@wustl.edu. 